\title{
Best Practices in Teachers' Professional Development in the United States
}

\author{
Laura M. DESIMONE* \& Michael S. GARET** \\ (*) University of Pennsylvania (**) American Institutes for Research \\ (United States of America) \\ (Received on February 6, 2015; Accepted on September 6, 2015)
}

\begin{abstract}
This paper discusses best practices in teachers' professional development (PD) in the United States (U.S.). We begin by presenting a conceptual framework for effective professional development, which suggests five key features that make professional development effective-content focus, active learning, coherence, sustained duration, and collective participation. We then describe the findings from recent U.S. research that has tested the five features, with an emphasis on the results of rigorous randomized control trials. We discuss several insights gained from this work and that have helped refine the framework. They are that (a) changing procedural classroom behavior is easier than improving content knowledge or inquiry-oriented instruction techniques; (b) teachers vary in response to the same PD; (c) PD is more successful when it is explicitly linked to classroom lessons; (d) PD research and implementation must allow for urban contexts (e.g., student and teacher mobility); and (e) leadership plays a key role in supporting and encouraging teachers to implement in the classroom the ideas and strategies they learned in the PD. We then examine three major trends in how professional development for teachers is evolving in the U.S. - a move away from short workshops, linking teacher PD to evaluations, and the use of video technology to improve and monitor the effects of PD. Finally, we discuss the challenges faced by districts and schools in implementing effective professional development.
\end{abstract}

Key words: teachers' professional development; high-quality professional development; causal studies of professional development; features of effective professional development

Correspondence: Professor Laura M. Desimone, Graduate School of Education/ University of Pennsylvania. Phone: 215-746-5699. Email: lauramd@gse.upenn.edu

\section{How to cite this article?}

Desimone, L. M., \& Garet, M. S. (2015). Best practices in teachers' professional development in the United States. Psychology, Society and Education, 7(3), 252-263. 


\section{Introduction}

This paper discusses best practices in teachers' professional development (PD) in the United States (U.S.). We begin by presenting a conceptual framework for effective professional development, which suggests five key features that make professional development effective. We then describe the findings from recent U.S. research that has tested the five features. Insights gained from this work have helped refine the framework in several critical ways, which we discuss. We then examine major recent trends in how professional development for teachers is evolving in the U.S., and the challenges faced by districts and schools in implementing effective PD.

\section{A Conceptual Framework for Effective Professional Development}

There is considerable evidence from research in the U.S. that for PD to be effective in improving teaching practice and student learning, at least five features need to be in place: (a) content focus: activities that are focused on subject matter content and how students learn that content; (b) active learning: opportunities for teachers to observe, receive feedback, analyze student work, or make presentations, as opposed to passively listening to lectures; (c) coherence: content, goals, and activities that are consistent with the school curriculum and goals, teacher knowledge and beliefs, the needs of students, and school, district, and state reforms and policies; (d) sustained duration: PD activities that are ongoing throughout the school year and include 20 hours or more of contact time; and (e) collective participation: groups of teachers from the same grade, subject, or school participate in PD activities together to build an interactive learning community (see Desimone, 2009).

Evidence supporting the five features comes from cross-sectional studies (Garet, Porter, Desimone, Birman, \& Yoon, 2001), longitudinal studies (e.g., Desimone, Porter, Garet, Yoon, \& Birman, 2002; Desimone, Smith, \& Phillips, 2013), and literature reviews of qualitative and quasi-experimental studies (Desimone, 2009). Further, some recent randomized control trials have documented the success of such PD across different ages and subjects (e.g., Gersten, Dimino, Jayanthi, Kim, \& Santoro, 2010; Penuel, Gallagher, \& Moorthy, 2011).

Also notable, however, are the disappointing results of several other large-scale randomized control trials that tested PD with the five features (e.g., Garet et al., 2008; Garet et al., 2011). These studies have confirmed that it is not clear how to translate the five general features into effective practice. Certainly more studies are needed. But a careful look at both the successful and unsuccessful recent randomized control trials in PD provides emerging evidence that helps shape our understanding of how these general principles can be transformed into effective PD (see also Desimone \& Stuckey, 2014).

\section{Using Recent Evidence to Refine the Five-Feature Conceptual Framework}

By examining recent rigorous research on U.S. PD, researchers have drawn several insights that are being used to refine the five-feature conceptual framework in ways that 
have the potential to help districts and schools translate the ideas to practice. Here we discuss those insights, which focus on five ideas: (a) changing procedural classroom behavior is easier than improving content knowledge or inquiry-oriented instruction techniques; (b) teachers vary in response to the same PD; (c) PD is more successful when it is explicitly linked to classroom lessons; (d) PD research and implementation must allow for urban contexts (e.g., student and teacher mobility); and (e) leadership plays a key role in supporting and encouraging teachers to implement in the classroom the ideas and strategies they learned in the PD. While much of the research has been done in the U.S., the general principles would likely apply to other countries; there is no evidence suggesting otherwise.

\section{Differences in the target of PD}

Changing procedural classroom behavior is easier than improving content knowledge or inquiry-oriented instruction techniques. One finding is that discrete teacher behaviors are easier to change than either teacher content knowledge or complex instructional approaches. PD designed to foster teacher use of straightforward, specific tasks, such as increased references to print while reading aloud, or providing warm-up problems every day, has been shown to be successful and requires a modest number of hours (e.g., Piasta et al., 2010; Sailors \& Price, 2010). In contrast, changing teachers' subject-matter knowledge in meaningful ways is difficult, and complicated behavior changes, such as conceptual teaching in mathematics, are less tractable, even with a substantial amount of PD that has the core features (Garet et al., 2010).

This finding is directly related to the idea that the effectiveness of PD rests on two kinds of theories about teaching and learning. The first is a theory of change, or how well the PD elicits desired changes in teacher knowledge and instruction. The second is the theory of instruction, which relates to the extent to which the change in instruction improves student learning. PD can fail if either theory is wrong-either the PD failed to change instruction, or the changed method of instruction failed to improve student learning (Wayne, Yoon, Zhu, Cronen, \& Garet, 2008).

Focusing on the theory of (teacher) change, it could be that certain types of change are easier to elicit. Specifically, it is likely easier for PD to change teachers' procedures, and more difficult for it to change their underlying subject-matter knowledge or skill with reflective practice. For example, it is easier for teachers to alter a particular sequence of routines (e.g., point out the image references in text, or practice word-comprehension exercises for a certain amount of time each day) (see Piasta et al., 2010) than to foster higher-order discussion from students. The latter requires a certain level of content knowledge and understanding of how to elicit such discussion and conversation, making the required change deeper and less tractable (Cohen \& Ball, 1990).

Teachers find it easier to alter specific behaviors or routines that do not require new knowledge. This may be in part because simpler behaviors are not as dependent on 
the quality of implementation. For example, if offering more opportunities for student practice is closely linked to improved student learning, the nature and quality of those practice opportunities may not matter, but rather the amount of time spent on them is what drives improvement. In contrast, inquiry-oriented instruction is linked to student learning, but what drives improvement is the nature and quality of questioning and discussion that occurs during inquiry-oriented instruction, rather than just the amount of time spent (Smith, Desimone, \& Ueno, 2005). It stands to reason that improving the quality of what teachers do would be more difficult than simply increasing the amount of time spent on a specific behavior (e.g., practice problem sets).

Alternatively, focusing on the theory of learning, it could be that the specific behaviors targeted by PD are more powerful levers for improving student learning, compared with increasing teacher content knowledge or conceptual, inquiry-oriented instruction. But there is little evidence to suggest that this is the case. Instead, the evidence suggests that, when implemented with quality, inquiry-oriented instruction does have meaningful effects on student learning. The challenge lies in is designing sustainable PD that effectively fosters this type of instruction.

\section{Teachers vary in response to the same PD}

A second finding from recent work in the U.S. is that teachers vary considerably in their response to the same PD. This in turn creates variation in student outcomes. Teachers come to PD with varying levels of experience and content knowledge, and from various classroom contexts - for example, some teachers have substantial numbers of English language learners, while other have substantial numbers of students with behavior issues. These factors may influence what teachers want to and are able to learn from the PD activity (e.g., Roschelle et al., 2010).

This variation in teacher response to the same PD implies that PD should be calibrated to individual teacher needs. Such calibration, through linking PD with formal teacher evaluation, is one of the most visible trends in PD in the last five years or so (Youngs, 2013). Often described as "differentiated PD," this PD can take two forms. One is to provide a catalog of PD opportunities (online experiences, workshops, readings, and other activities), linked to areas of teacher practice measured in teacher observations. Teachers may then select opportunities in areas where they need improvement. The other approach is to draw on teacher evaluation data in coaching and mentoring, which allows coaches and mentors to tailor their work to particular areas of strength and weakness (Allen, Pianta, Gregory, Mikami, \& Lun, 2011). We don't yet know how well differentiated PD has been implemented, or whether it has the desired effects.

One challenge is how to successfully merge the idea of collective participation with differentiated PD. The goal is not to shift PD into a completely individualized experience but to provide collective experiences that are targeted to groups of teachers with similar needs and challenges. For example, the PD might provide different sessions 
or activities for teachers who are new to an intervention and those who have had some experience with it. This type of differentiated PD was accomplished in the implementation of a mathematics-based software program that used principles of cognitive science to help $6^{\text {th }}$ graders learn fractions and measurement. Different PD was offered to teachers depending on their knowledge level and experience with the software, and the results showed that teachers benefitted from this differentiation (Bowdon, Massey, \& Kregor, 2015).

\section{PD is more successful when it is explicitly linked to classroom lessons}

Recent PD studies guide us toward a greater understanding of the specific aspects of coherence that are especially important for teacher learning. Specifically, we find that alignment with the material the teacher is teaching is a powerful aspect of coherence.

For example, Santagata, Kersting, Givvin, and Stigler (2011), in a randomized control trial of a math PD, aligned the training materials with the teacher's curriculum, to ensure that "teachers received PD on a particular topic area immediately before they were to teach it to their students" (p. 70). Variation in pacing across teachers interfered, so for as many as $50 \%$ of teachers, the pacing did not match. The researchers found that implementation and effects were significantly better for teachers whose pacing was aligned with the PD - that is, the PD they received was directly aligned to the lesson they were to teach immediately after the PD. Similarly, the PD that Penuel and his colleagues (2011) offered was completely and explicitly linked to the curriculum teachers were using to teach middle school earth science. Students whose teachers participated had significantly higher science achievement than those who did not.

Similarly, several researchers attribute the failure of their PD programs to the lack of a direct link to teachers' classroom lessons. One hypothesis for the disappointing results of very intensive content-focused $\mathrm{PD}$, such as that studied by Garet and colleagues $(2008,2011)$, is that PD is less effective when it does not help teachers translate the knowledge or strategies into daily instructional routines and lessons.

These studies suggest that in designing PD, we should consider carefully the ease with which the PD can be integrated into teacher lessons. We ought to take on the issue of alignment with lessons more deliberately, and include support, guidance, and practice for teachers to integrate the knowledge or pedagogy into their daily instruction, rather than leaving that burden to them when they return to the classroom.

\section{$P D$ research and implementation must allow for conditions in urban areas}

A fourth lesson from recent randomized control trials is that in both the study and design of PD, we would be well-served to take into account certain conditions that commonly occur in urban school contexts in the U.S. Namely, high principal, teacher, and student mobility in and out of the school, as well as within-teacher movement from grade to grade. In U.S. schools, teachers often switch schools from one year to the next, or are assigned to teach different grades or subjects. Similarly, students often change 
schools for various reasons, including their family moving to a different neighborhood in the district. PD programs must become adept at responding to the realities of principal, teacher, and student mobility. For example, decisions related to the timing and intensity of training, retraining opportunities, and timing of student exposure over the school year, should consider the ebb and flow of urban populations to better account for the instability that, unfortunately, is currently a stable condition in most urban schools in the U.S. (Garet, 2012). For example, training programs could develop ways to train teachers who enter the school in the middle of the year, and ways to analyze data that takes into account the fact that some students will have been exposed to the intervention for only part of the year, if they entered the school in the fall or spring.

\section{Leadership plays a key role in supporting and encouraging teachers to implement in the classroom the ideas and strategies they learned in PD}

Finally, research has demonstrated that teachers are more likely to use ideas and strategies from PD when they are aligned with leadership priorities. Leaders play a critical role in providing time for teachers to participate in and practice what is learned in PD. Further, they can also play a role in including the PD activities in the evaluation of the teachers. District and school leaders' supports and enthusiasm for PD play an influential role in teacher ability, willingness, and motivation to take up ideas, activities, and curricula promoted in PD (Desimone, 2002). This idea is consistent with theories about the role that leaders and incentives play in shaping teacher actions (e.g., Porter, Archbald, \& Tyree, 1990).

\section{Current Trends in U.S. PD}

In addition to these recent findings, which contribute to our understanding of how best to shape and implement teacher PD, several trends in teacher PD are also influencing the nature and quality of teacher PD in the U.S.

One recent trend in the U.S. is a move away from one-time workshops, which in the U.S. have been common. In one-time workshops, teachers meet for 1-3 hours to listen to a lecture on an isolated topic. National data show that in the past couple of decades districts have moved away from these kinds of short workshops toward PD that attempts to adopt the five core features described above (Smith \& Desimone, 2003). For example, analysis of the nationally representative Schools and Staffing Survey shows that fewer than 20\% of U.S. teachers had eight hours or fewer of PD in the 2011-2012 school year (U.S. Department of Education, 2012). A national study of PD in the U.S. showed that the percent of teachers participating in PD related to the content they teach increased from 59\% in 2000 to $83 \%$ in 2004 and $87 \%$ in 2008 (Wei, Darling-Hammond, \& Adamson, 2010). These figures suggest that PD providers increasingly understand the importance of sustained, content-focused $\mathrm{PD}$, and are directing resources to ensuring that teachers have access to such activities. 
Another trend, as discussed above, is the linking of PD to teacher evaluations. This is becoming more and more common, and it is driving improvements in how we organize, administer, and evaluate PD. Principals are increasingly including in their yearly evaluations measures of how well teachers are implementing the knowledge and practice they learned in PD. This creates a more coherent policy cycle, where the PD activities teachers engage in are explicitly valued and monitored by their school leaders, and become a formal part of the evaluation system.

Yet a third new direction in PD is the increased use of video as a tool for classroom observation and coaching. For example, the availability of new, low-cost video technology has made it possible for teachers' classes to be video-taped multiple times over a school year and then coded by a distant coach. A recent study by Allen and colleagues (2011) has shown potentially positive effects of video-based coaching on teachers' classroom instruction and student achievement.

Another potentially compelling use of video is to provide a catalogue of resources for teachers. For example, several states provide free videos providing examples of several ways to teach to particular state standards, and teachers can use these as realtime resources as they plan their daily lessons (Council of Chief State School Officers, n.d.). There is no reliable data on how often teachers use such resources or how effective those resources are for improving instruction, so this is an area ripe for further research.

Recent development of a series of high-quality classroom observation rubrics, such as the Mathematics Quality of Instruction (MQI) (Hill et al., 2008) and the Instructional Quality Assessment (IQA) (Junker et al., 2006), increase the potential uses of classroom videos. With video-recordings of classrooms, administrators and researchers can use multiple protocols to code the observation on multiple dimensions, thus enriching the potential of the data.

\section{Challenges}

These new understandings and trends in teacher PD are accompanied by several challenges. One major challenge to PD in the U.S. is the tension between having multiple providers and trying to achieve coherence. As a result, the PD teachers experience is often fragmented, with little continuity across PD opportunities, and little cumulative design. PD is offered under many auspices. Some PD is offered by states, some by districts, some by colleges and universities, some by publishers, and some by independent consultants and organizations. PD has many different purposes.

Some PD is designed to support the implementation of a new curriculum or program; some to improve teachers' content knowledge in a particular discipline (e.g., algebra or biology); some is designed to support teachers in learning new approaches to pedagogy (e.g., differentiated instruction); and some is designed to focus on special populations (e.g., English language learners). PD is also funded and governed in many different ways. And though the "one-shot" workshop has proven to be ineffective, some districts still use this model because they do not have the resources or capacity to design 
and provide more coherent, comprehensive PD opportunities for teachers. Furthermore, it is difficult for schools and districts to obtain a comprehensive understanding of the PD opportunities available, or of any particular teacher's experiences (Wilson, Rozelle, \& Mikeska, 2011).

This multiplicity of PD also makes it difficult to learn from studies of PD. That is, PD varies in so many ways that it is difficult to draw conclusions about which factors contribute to the success or failure of PD efforts. Very specific features of the PD need to be manipulated to isolate their influence (see Penuel et al., 2011). Another challenge to studying PD is that the tracking of teacher PD is not strong in most districts. If districts did a better job of monitoring and recording the PD experiences of teachers, these data could be used in longitudinal administrative data systems to help identify patterns of participation, and eventually link those participation patterns with results for teachers and students.

Another major challenge, as we discussed earlier, is being explicit about what teachers are supposed to learn from the PD. In many cases, the theory of action needs to be more completely specified than is typically done. For example, for a PD designed to increase content knowledge, how is that knowledge expected to be translated into the classroom in ways that improve student learning? The explicit linking of ideas or behaviors taught in the PD to the text, lessons, and other material the teachers are using in the classroom has proven in many cases to be a powerful, and perhaps necessary, piece of the puzzle (e.g., Santagata et al., 2011).

\section{Next Steps}

In the context of these insights and challenges, there are several reasons to think that research and development on PD may advance over the next decade. First, in the U.S., new measures of teacher outcomes have been developed. In particular, we now have at least some measures of teachers' content knowledge (e.g., Hill, Rowan, \& Ball, 2005). Second, the increased availability of video may make it easier to examine the relationship between $\mathrm{PD}$ and change in teaching practice.

Third, the increased availability of teacher value-added measures makes it possible to examine the relationship between participation in PD and change in teacher effectiveness (at least as measured in terms of student test gains). The availability of these sorts of measures can support quasi-experimental studies. A major challenge here, though, is obtaining data on teacher participation in PD, given the fragmented opportunities typically offered to teachers, coupled with the fact that few districts collect data on teacher participation in PD. Some states and districts have begun to catalogue teacher PD participation, and these data could be linked with longitudinal achievement data in many states.

Lastly, there is increasing potential in conducting quick-turnaround randomized trials in the context of rolling out new PD opportunities. For example, if a district plans to allocate PD to teachers with identified needs based on the teacher evaluation system, 
in the first year, some teachers could be randomly assigned to receive intensive PD, and their evaluation results could then be carefully monitored. This type of research would allow results to be collected more quickly than typical randomized control trials, which take 1-3 years.

\section{Conclusion}

There is substantial evidence that the five core features have been adopted as "best practice" by a number of countries (Kennedy, 2014), and that other developed countries have similar challenges to teacher PD as the ones faced by U.S. teachers, as described here (e.g., Jones, 2011; O'Brien, 2011). However, work needs to be done to take PD research to the next level, specifically in translating the broad features into specific, effective activities in varying contexts. We need more information about specific aspects of the five features that are important in different contexts, in order to form a better understanding of why some PD works and some doesn't.

In terms of designing and providing high-quality PD, establishing periodic monitoring and feedback loops is essential. Such monitoring can help providers, whether they are schools, districts, or others, create a cycle of continuous improvement. Further, it allows the potential for identifying weaknesses in any of the five core features, which can then be addressed. Another area we would emphasize is building a rigorous evaluative component into PD, so that we can continue to increase our understanding of why some PD activities are effective and others aren't.

\section{References}

Allen, J. P., Pianta, R. C., Gregory, A., Mikami, A. Y., \& Lun, J. (2011). An interaction-based approach to enhancing secondary school instruction and student achievement. Science, 333, 1034-1037.

Bowdon, J., Massey, C., \& Kregor, J. (2015). Unpacking implementation of a mathematicsbased software intervention. Philadelphia, PA: Cognitive Science Center, University of Pennsylvania.

Cohen, D., \& Ball, D. L. (1990). Relations between policy and practice: A commentary. Educational Evaluation and Policy Analysis, 12(3), 249-256.

Council of Chief State School Officers. (n.d.).

http://www.ccsso.org/resources/digital_resources/common_core_implementation_video series.html

Desimone, L. (2002). How can comprehensive school reform models be successfully implemented? Review of Educational Research, 72(3), 433-479.

Desimone, L. M. (2009). Improving impact studies of teachers' professional development: Toward better conceptualizations and measures. Educational Researcher, 38(3), 181199.

Desimone, L., Porter, A. C., Garet, M., Yoon, K., \& Birman, B. (2002). Effects of professional development on teachers' instruction: Results from a three-year study. Educational Evaluation and Policy Analysis, 24(2), 81-112. 
Desimone, L., Smith, T., \& Phillips, K. (2013). Linking student achievement growth to professional development participation and changes in instruction: A longitudinal study of elementary students and teachers in Title I schools. Teachers College Record, 115(5), $1-46$.

Desimone, L., \& Stuckey, D. (2014). Sustaining professional development. In. L. Martin, S. Kragler, D. Quatroche, \& K. Bauserman (Eds.), Handbook of professional development in education: Successful models and practices, prek-12 (pp. 467-482). New York, NY: Guilford Publications.

Garet, M. (2012, March). Recommendations for professional development. In Supporting implementation of the Common Core State Standards for mathematics (pp. 59-60). Washington, DC: CCSSO and North Carolina State University.

Garet, M. S., Cronen, S., Eaton, M., Kurki, A., Ludwig, M., Jones, W., Uekawa, K., ... Silverberg, M. (2008). The impact of two professional development interventions on early reading instruction and achievement. Washington, DC: National Center for Education Evaluation and Regional Assistance, Institute of Education Sciences, U.S. Department of Education.

Garet, M., Porter, A., Desimone, L., Birman, B., \& Yoon, K. (2001). What makes professional development effective? Analysis of a national sample of teachers. American Education Research Journal, 38(3), 915-945.

Garet, M., Wayne, A., Stancavage, F., Taylor, J., Eaton, M., Walters, K., \& Doolittle, F. (2011). Middle school mathematics professional development impact study: Findings after the second year of implementation (NCEE 2011-4024). Washington, DC: National Center for Education Evaluation and Regional Assistance, Institute of Education Sciences, U.S. Department of Education.

Garet, M. S., Wayne, A. J., Stancavage, F., Taylor, J., Walters, K., Song, M., \& Doolittle, F. (2010). Middle school mathematics professional development impact study: Findings after the first year of implementation (NCEE 2010-4009). Washington, DC: National Center for Education Evaluation and Regional Assistance, Institute of Education Sciences, U.S. Department of Education.

Gersten, R., Dimino, J., Jayanthi, M., Kim, J. S., \& Santoro, L. E. (2010). Teacher study group: Impact of the professional development model on reading instruction and student outcomes in first grade classrooms. American Educational Research Journal, 47(3), 694-739.

Hill, H. C., Rowan, B., \& Ball, D. L. (2005). Effects of teachers' mathematical knowledge for teaching on student achievement. American Educational Research Journal, 42(2), 371406. doi: 10.3102/00028312042002371

Hill, H. C., Blunk, M., Charalambous, C., Lewis, J., Phelps, G. C., Sleep, L., \& Ball, D. L. (2008). Mathematical knowledge for teaching and the mathematical quality of instruction: An exploratory study. Cognition and Instruction, 26, 430-511.

Jones, K. (2011). Central, local and individual continuing professional development (CPD) priorities: Changing policies of CPD in Wales. Professional Development in Education, 37(5), 759-776.

Junker, B. W., Matsumura, L. C., Crosson, A., Wolf, M. K., Levison, A., Wiesberg, J., \& Resnick, L. (2006). Overview of the Instructional Quality Assessment (CSE Technical 
Report 671). Los Angeles, CA: University of California, National Center for Research on Evaluation, Standards, and Student Testing.

Kennedy, A. (2014). Understanding continuing professional development. Professional Development in Education, 40(5), 688-697.

O'Brien, J. (2011). Continuing professional development for Scottish teachers-tensions in policy and practice. Professional Development in Education, 37(5), 777-792.

Penuel, W. R., Gallagher, L. P., \& Moorthy, S. (2011). Preparing teachers to design sequences of instruction in earth systems science: A comparison of three professional development programs. American Educational Research Journal, 48(4), 996-1025.

Piasta, S. B., Dynia, J. M., Justice, L. M., Pentimonti, J. M., Kaderavek, J. N., \& Schatschneider, C. (2010). Impact of professional development on preschool teachers' print references during shared read alouds: A latent growth curve analysis. Journal of Research on Educational Effectiveness, 3(4), 343-380.

Porter, A., Archbald, D., \& Tyree, Jr., A. (1990). Reforming the curriculum: Will empowerment policies replace control? In S. H. Fuhrman \& B. Malen (Eds.), The politics of curriculum and testing: The 1990 yearbook of the Politics of Education Association (pp. 11-36). New York: Falmer.

Roschelle, J., Shechtman, N., Tatar, D., Hegedus, S., Hopkins, B., Empson, S., Knudsen, J., \& Gallagher, L. P. (2010). Integration of technology, curriculum, and professional development for advancing middle school mathematics: Three large-scale studies. American Educational Research Journal, 47(4), 833-878.

Sailors, M., \& Price, L. R. (2010). Professional development that supports the teaching of cognitive reading strategy instruction. The Elementary School Journal, 110(3), 301-322.

Santagata, R., Kersting, N., Givvin, K. B., \& Stigler, J. W. (2012). Problem implementation as a lever for change: An experimental study of the effects of professional development program on students' mathematics learning. Journal of Research on Educational Effectiveness, 4(1), 1-24. doi: 10.1080/19345747.2010.498562

Smith, T., \& Desimone, L. (2003). Do changes in patterns of participation in teachers' professional development reflect the goals of standards-based reform? Educational Horizons, 81(3), 119-129.

Smith, T. M., Desimone, L. M., \& Ueno, K. (2005). "Highly qualified" to do what? The relationship between NCLB teacher quality mandates and the use of reform-oriented instruction in middle school math. Educational Evaluation and Policy Analysis, 27(1), 75-109.

U.S. Department of Education. (2012). National Center for Education Statistics, Schools and Staffing Survey (SASS), Public and Private Teachers Data File.

Wayne, A. J., Yoon, K. W., Zhu, P., Cronen, S., \& Garet, M. S. (2008). Experimenting with teacher professional development: Motives and methods. Educational Researcher, 37, 469-279. doi: 10.3102/0013189X08327154

Wei, R. C., Darling-Hammond, L., \& Adamson, F. (2010). Professional development in the United States: Trends and challenges. Dallas, TX: National Staff Development Council.

Wilson, S. M., Rozelle, J. J., \& Mikeska, J. N. (2011). Cacophony or embarrassment of riches: Building a system of support for quality teaching. Journal of Teacher Education, 62, 383-394

(C) Psy, Soc, \& Educ, 2015, Vol. 7(3) 
Youngs, P. (2013). Using teacher evaluation reform and professional development to support Common Core assessments. Washington, DC: Center for American Progress. Retrieved http://cdn.americanprogress.org/wp-content/uploads/2013/01/YoungsCommonCore.pdf 